БРОДОВСКАЯ Елена Викторовна - доктор политических наук, профессор департамента политологии факультета социальных наук и массовых коммуникаций, директор центра политических исследований Финансового университета при Правительстве РФ (125993, Россия, г. Москва, ГСП-3, Ленинградский пр-кт, 49; brodovskaya@inbox.ru)

ЛУКУШИН Владимир Андреевич - лаборант-исследователь центра политических исследований, студент факультета социальных наук и массовых коммуникаций Финансового университета при Правительстве РФ (125993, Россия, г. Москва, ГСП-3, Ленинградский пр-кт, 49; lukushin@aol. com)

\title{
ЦЕННОСТНОЕ КАМУФЛИРОВАНИЕ В ИНФОРМАЦИОННЫХ ПОТОКАХ РОССИЙСКИХ ПОЛИТИЧЕСКИХ ПАРТИЙ
}

\begin{abstract}
Аннотация. В статье представлены результаты прикладного политического исследования, посвященного использованию российскими политическими партиями ценностного камуфлирования - современной технологии взаимодействия с таргетными группами в цифровом пространстве. На основе применения автоматизированного социально-медийного анализа и когнитивного картирования цифрового партийного контента определены масштаб, особенности и эффекты подобной ценностной маскировки. Авторы пришли к выводу, что наметившийся в последние год под влиянием негативных эффектов пандемии COVID-19 «левый поворот» в развитии общественных настроений и ожиданий подталкивает политические партии к изменению собственной повестки, а также отказу от устоявшихся политических позиций в соответствии с актуальными запросами значительной части избирателей.

Ключевые слова: политические партии, информационные потоки, социально-медийная аналитика, ценностное камуфлирование, цифровой менеджмент, цифровые инфраструктуры, когнитивное картирование

Исследование выполнено при финансовой поддержке РФФИ и ЭИСИ в рамках научного проекта № 21-011-33015 “"Левый поворот” в развитии партийной системы и электоральных ожиданий граждан РФ(2020-2021 г2.)».
\end{abstract}

Постановка проблемы. Выборы депутатов Государственной думы ФС РФ 2021 г. продемонстрировали значительную технологическую трансформацию избирательной кампании. Большое влияние на предвыборную агитацию и коммуникацию с таргетными группами оказали современные социальные медиа, ставшие полноценными инструментами для целого ряда политических партий и кандидатов. Можно утверждать, что цифровизация избирательного процесса является ключевым трендом, приспособление к которому напрямую влияет на электоральный результат [Азаров, Бродовская, Лукушин 2021]. Цифровое пространство предоставляет пользователям широкий круг возможностей для реализации различных форматов политического участия, чем активно пользуются политические партии [Пырма 2019]. В то же время проблема организации системы цифровых коммуникаций и сопровождение деятельности партии в онлайн-пространстве вызывает затруднения как для традиционных, так и для новых партийных акторов [Бродовская и др. 2021].

В условиях массовых эпидемиологических ограничений в связи с пандемией COVID-19 политические партии оказались перед вызовом. С одной стороны, пандемия ограничивает возможности прямой коммуникации с электоратом, с другой - цифровые инструменты позволяют адаптироваться к меняющимся 
общественным настроениям и ожиданиям. Отечественные партии уже освоили ряд цифровых технологий взаимодействия с электоратом посредством выстраивания фирменного контента, создания необходимого информационного фона, использования манипулятивных практик [Васильев, Водопетов, Антонович 2020]. С начала 2020 г. при оценке цифрового партийного менеджмента было зафиксировано масштабное использование ценностного камуфлирования. Данная технология позволяет партиям успешно маскироваться под актуальные запросы вне зависимости от устоявшейся идеологической позиции путем формирования соответствующего информационного потока.

Зарубежные исследователи отмечают, что идеологические позиции политических партий по всему миру проявляют слабость и неустойчивость [Faustino et al. 2019]. Наиболее подвержены данным процессам небольшие партии, а также партии, существующие в относительно молодых партийных системах при отсутствии сильных традиций парламентаризма. Во-многом мы имеем дело с ценностным кризисом, связанным с необходимостью для партий отказываться от сформированных позиций и убеждений под влиянием меняющихся общественных настроений. На этом фоне усиливаются процессы партийной дезинтеграции и фрагментации [Volpi 2019]. Кроме того, многоуровневый анализ массива электоральной статистики, проведенный европейскими исследователями, показывает, что в молодых, слабо институционализированных партийных системах чаще всего проявляются затруднения в определении идеологических позиций крупнейших партий среди избирателей [Busch 2016]. Особое внимание исследователей приковано к посткоммунистическим странам Центральной и Восточной Европы, где процесс институционализации партийных систем столкнулся с рядом внутренних проблем [Чепель 2019]. Исследователи доказывают, что партии в подобных системах все чаще склонны менять позиции по ключевым вопросам, исходя из динамики общественного мнения, даже если это противоречит базовым партийным ценностям и убеждениям.

Целью текушего прикладного исследования стало определение масштаба, особенностей и эффектов использования технологии ценностного камуфлирования в информационных потоках российских политических партий в ходе избирательной кампании 2021 г.

Методология и методика исследования. Методология исследования опирается на использование нового для прикладных исследований подхода Predictor Mining. Сущность подхода заключается в составлении банка маркеров цифровой социально-политической активности и их дальнейшей обработке посредством автоматизированных методов и инструментов социального компьютинга [Бродовская и др. 2017]. Одним из актуальных направлений использования Predictor Mining является анализ, сценирование и прогнозирование цифровых коммуникаций политических партий, а также оценка эффективности их цифрового менеджмента [Бродовская 2020].

Методика исследования включает в себя проведение нескольких этапов когнитивного картирования цифрового контента 10 российских политических партий. Критериями выборки стали показатели партий по результатам ЕДГ-2020, электоральные возможности и шансы в ходе думской кампании, а также предварительная оценка качества управления информационными потоками, проведенная на предыдущих этапах исследования. В ходе анализа проанализированы 1100 публикаций в крупнейших партийных аккаунтах в 5 крупнейших социальных медиа. Публикации были отобраны исходя из цели охватить различные временные промежутки (в начале пандемии COVID-19 и в разгар каждой из эпидемиологических волн). Совокупная глубина анализа: 
01.03.2020-01.10.2021. Для обработки полученной базы применяется инструмент статистического анализа SPSS Statistics V23. Автоматизированный киберметрический анализ проведен на основе сформированных словарей поисковых запросов посредством сервиса мониторинга социальных медиа IQBuzz. Общий датасет составил 10 млн сообщений за 2020-2021 гг., размещенных на 30 наиболее популярных цифровых платформах.

Результаты исследования. Пандемия COVID-19 не только ускорила освоение партийными акторами цифровых каналов и технологий коммуникаций, но и способствовала артикулированию интересов групп, ориентированных на левые идеи и ценности, усиление социальных функций государства. В этой связи в информационном пространстве в период электорального цикла 2021 г. партии активно демонстрировали камуфлирование под левые идеологические модели. В целом, развитие российской партийной системы на текущем этапе можно охарактеризовать как «левый поворот». Данный термин уже активно использовался в отечественной науке при описании внутриполитических процессов в странах Латинской Америки [Дабагян 2008; Пименова 2009], а также идеологических трансформаций европейских партий [Работяжев 2012].

В этой связи наибольшее камуфлирование продемонстрировали партии, не являющиеся четкими представителями левого фланга партийной системы, а также партии со сложной идеологической идентификацией (см. табл. 1). Когнитивное картирование отобранного массива публикаций свидетельствует о широком распространении технологии ценностного камуфлирования в информационных потоках всех политических партий (используется в $42 \%$ всех публикаций, в $71 \%$ публикаций «не левых» партий). При этом информационный поток левых партий демонстрирует дальнейшее усиление собственной повестки, выраженное в политизации, идеологизации цифрового контента, а также увеличении эмоциональной окраски большинства публикаций, повышении частоты упоминания ключевых для партий дискурсов и требований, традиционно относящихся к левым (социальная повестка, государственное регулирование экономики, патернализм, общественная солидарность).

Таблица 1

Использование технологии ценностного камуфлирования российскими политическими партиями, \%

\begin{tabular}{|l|c|}
\hline \multicolumn{1}{|c|}{ Партия } & Доля контента \\
\hline «Единая Россия» & 67,2 \\
\hline «Новые люди» & 62,3 \\
\hline «Зеленая Альтернатива» & 57,4 \\
\hline ЛДПР & 54,1 \\
\hline «Яблоко» & 18,3 \\
\hline
\end{tabular}

Предыдущие этапы исследования, посвященные оценке конкурентности партийных информационных потоков, позволяют связать качество цифрового партийного менеджмента с масштабом ценностного камуфлирования. Партии, для которых характерен высокий уровень развития системы цифровых коммуникаций, чаще прибегают к использованию ценностного камуфлирования. Для объяснения данной закономерности обратимся к эффектам применения данной технологии, выраженных в характере пользовательских реакций 
(отношение пользователей к подобному цифровому контенту посредством просмотров, лайков и комментариев). По результатам статистической обработки собранной базы обнаружен ряд корреляционных связей. Публикации с использованием ценностного камуфлирования привлекают больше внимания интернет-пользователей, активизируют их цифровую активность, увеличивая возможности вовлечения аудитории в партийные информационные потоки. Кроме того, зафиксировано превышение показателей пользовательской активности в публикациях с использованием ценностного камуфлирования в сообществах и аккаунтах отдельных политических партий («Новые люди», «Яблоко», ЛДПР).

Анализ динамики использования технологии ценностного камуфлирования показывает, что ее представленность увеличивается в среднем на четверть в периоды ухудшения эпидемиологической ситуации (апрель, ноябрь 2020 г., февраль, май 2021 г.). Для подтверждения обозначенной гипотезы о влиянии COVID-19 на процессы партийного камуфлирования произведен расчет упоминаний тем, напрямую связанных с пандемией в совокупном потоке каждой партии. Для этого выделены специальные тематические маркеры («пандемия», «ковид», «масочный режим», «вакцинация», «удаленка», «дистант» и др.), указывающие на упоминание соответствующей темы. Полученные результаты в целом подтверждают выдвинутую гипотезу (см. рис. 1). Автоматизированная обработка социальных медиа позволила выделить три уровня партий: с высокой (более $15 \%)$, средней $(5-15 \%)$ и низкой (менее $5 \%)$ представленностью подобного цифрового контента. Традиционные левые партии уделили теме пандемии меньше внимания, чем ряд партий-конкурентов, активно работающих с актуальной повесткой, в наибольшей степени волнующей избирателя. Таким образом, партии - лидеры по использованию технологии ценностного камуфлирования демонстрируют наибольшие показатели упоминания пандемийных тем («Единая Россия» и «Новые люди»).

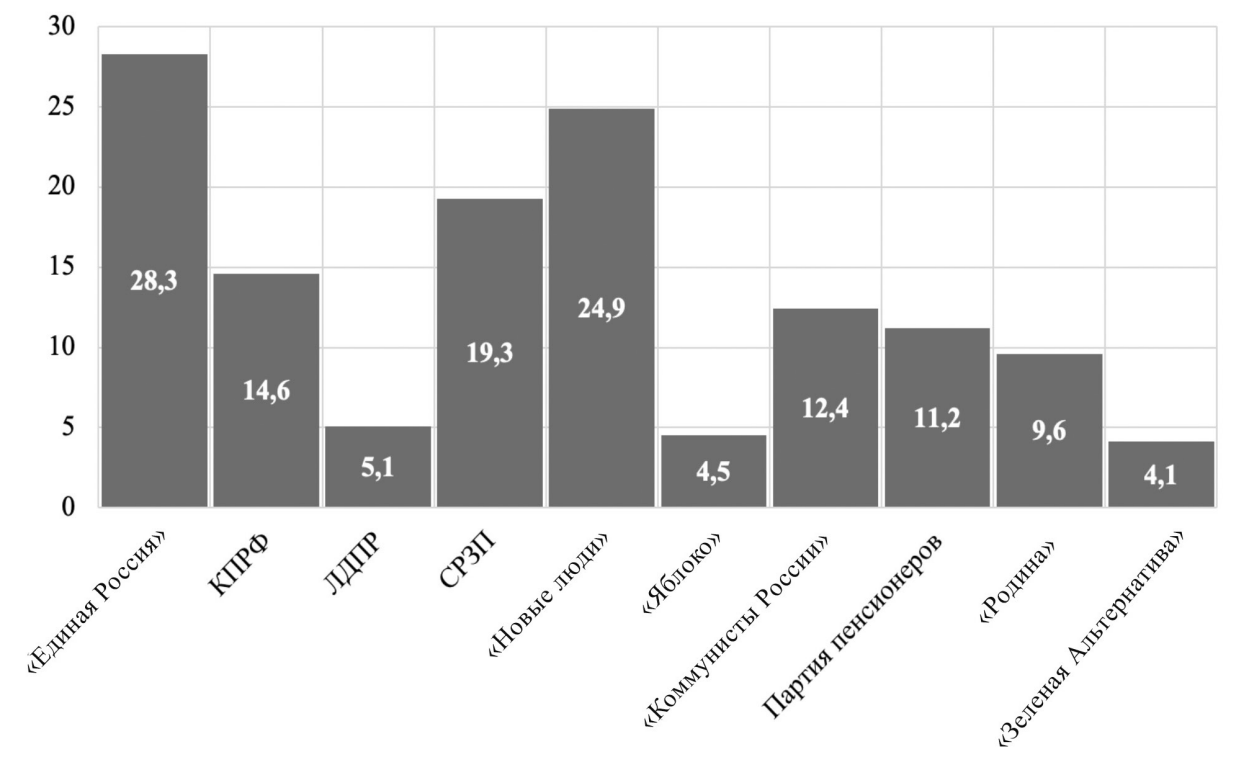

Рисунок 1. Доля публикаций с упоминанием пандемии COVID-19 в партийных информационных потоках, \% 
На заключительном этапе исследования была предпринята попытка оценить характер выбранной модели камуфлирования. Авторы были отобрали основные левые модели, соответствующие отечественным традициям изучения политических идеологий: социал-демократическую, классическую социалистическую/коммунистическую, национал-патриотическую, радикальную анархистскую (см. табл. 2). Маркерами определения идеологической модели стали выдвигаемые партийные требования и заявления, а также формируемые партией в конкретный момент времени ориентиры, установки и образы будущего. По итогам анализа рассчитана представленность каждой из выделенных моделей в общем потоке всех партий. Ожидаемо наиболее распространенной моделью камуфлирования является социал-демократическая (более приближенная к современной западноевропейской системе), отличающаяся простотой и практичностью идей, системностью и конвенциональностью требований, что отвечает основным запросам российского общества, активно формируемым в последние годы ${ }^{1}$. Большим успехом среди ряда партий и их аудиторий пользуется советская модель в контексте инструментов регулирования экономики и повышенной социальной ответственности государства. Необходимо отметить, что партийное камуфлирование в радикальные и неконвенциональные модели (националистические, анархистские) не пользуется популярностью среди политических партий. Редкое апеллирование партий к данным моделям встречает крайне низкий интерес среди аудитории.

Таблица 2

Представленность идеологических моделей левого типа в партийных информационных потоках, \%

\begin{tabular}{|l|c|}
\hline \multicolumn{1}{|c|}{ Модель } & Представленность \\
\hline Социал-демократическая & 67,8 \\
\hline Социалистическая & 26,3 \\
\hline Национал-патриотическая & 4,8 \\
\hline Радикал-анархистская & 1,1 \\
\hline
\end{tabular}

Заключение. По результатам проведенного прикладного исследования можно сделать ряд выводов. Во-первых, в период избирательной кампании по выборам депутатов Государственной думы ФС РФ 2021 г. в условиях масштабной цифровизации электорального процесса политические партии продолжают осваивать современные технологии взаимодействия с таргетными группами. Одной из ключевых технологий можно считать ценностное камуфлирование, связанное с маскировкой продвигаемых партией идей и образов, ориентированных на актуальную общественную повестку, соответствующих текущим запросам значительной части избирателей.

Во-вторых, в ходе кампании различные политические партии активно используют технологию ценностного камуфлирования в цифровом пространстве. Если традиционные левые партии усиливают информационную повестку под влиянием внешних факторов, то их ключевые конкуренты осуществляют полноценную маскировку посредством разнообразия контента, использова-

\footnotetext{
1 Альтернативы для России: каким видят будущее страны сторонники и противники перемен. - Московский центр Карнеги. Доступ: https://carnegie.ru/2020/11/09/ru-pub-83153 (проверено 18.10.2021).
} 
ния новых инфоповодов и изменения устоявшихся позиций по целому ряду значимых для общества вопросов.

В-третьих, основным фактором, влияющим на процесс камуфлирования, стали негативные эффекты пандемии $C O V I D-19$, усилившие тенденцию левого поворота в развитии общественных настроений, запрос на патерналистскую повестку, масштабную и справедливую социальную политику и государственное регулирование экономики.

В-четвертых, авторы зафиксировали взаимосвязь между использованием технологии ценностного камуфлирования, качеством цифрового партийного менеджмента и особенностями пользовательских реакций, что свидетельствует о позитивном восприятии целевыми аудиториями подобного контента и попадании партий в «климат ожиданий» избирателей.

К перспективам проведенного прикладного исследования можно отнести проведение киберметрического анализа информационных потоков и цифровых сообществ, формирующих левые дискурсы в цифровом пространстве, а также применение методики социального графа для понимания структурных характеристик левого информационного потока.

\section{Список литературы}

Азаров А.А., Бродовская Е.В., Лукушин В.А. 2021. Цифровые сообщества новых политических партий в России (2020 г.). - Власть. Т. 29. № 1. С. 77-83.

Бродовская Е.В. 2020. Цифровой менеджмент в деятельности российских политических партий: проблемное поле управления информационными потоками в социальных медиа. - Власть. Т. 28. № 6. С. 81-88.

Бродовская Е.В., Домбровская А.Ю., Карзубов Д.Н., Синяков А.В. 2017. Развитие методологии и методики интеллектуального поиска цифровых маркеров политических процессов в социальных медиа. - Мониторинг общественного мнения: экономические и социальные перемены. № 5. С. 79-104.

Бродовская Е.В., Лифанова В.А., Лукушин В.А., Семенова М.С. 2021. Цифровые инфраструктуры традиционных и новых российских политических партий: масштаб и функциональность (2020). - Социально-гуманитарные знания. № 3. С. 194-204.

Васильев М.С., Водопетов С.А., Антонович С.А. 2020. Цифровые коммуникативные технологии на региональных выборах: применение властью и оппозицией. - Известия Тульского государственного университета. Гуманитарные науки. № 2. С. 39-49.

Дабагян Э.С. 2008. «Левый поворот» в Латинской Америке. - Свободная мысль. № 2. С. 63-74.

Пименова Р.А. 2009. Роль этнических факторов в «левом повороте» стран Латинской Америки. - Региональные исследования. № 1. С. 34-37.

Пырма Р.В. 2019. Влияние цифровых коммуникаций на политическое участие. - Гуманитарные науки. Вестник Финансового университета. № 4. С. 63-69.

Работяжев Н.В. 2012. Европейская социал-демократия в поисках адаптации к меняющемуся миру. - Полития. № 3. С. 146-167.

Чепель С.Л. 2019. Динамика электоральной активности и проблемы консолидации «новых демократий» в посткоммунистических странах Европы. Гуманитарные науки. Вестник Финансового университета. № 5. С. 6-14.

Busch K.B. 2016. Estimating Parties' Left-Right Positions: Determinants of Voters' Perceptions' Proximity to Party Ideology. - Electoral Studies. Vol. 41. P. 159-178.

Faustino J., Barbosa H., Ribeiro E., Menezes R. 2019. A Data-Driven Network Approach for Characterization of Political Parties' Ideology Dynamics. - Applied Network Science. Vol. 4. No. 48. P. 1-15. 
Volpi E. 2019. Ideology and Party Switching. A Comparison of 12 West European Countries. - Parliamentary Affairs. Vol. 72. No. 1. P. 1-20.

BRODOVSKAYA Elena Viktorovna, Dr.Sci. (Pol. Sci.), Professor of the Department of Political Science, Faculty of Social Sciences and Mass Communications, Director of the Center for Political Studies, Financial University under the Government of the Russian Federation (49 Leningradsky Ave, GSP-3, Moscow, Russia, 1259930; brodovskaya@inbox.ru) LUKUSHIN Vladimir Andreevich, Research Assistant at the Center for Political Studies, student of the Faculty of Social Sciences and Mass Communications, Financial University under the Government of the Russian Federation (49 Leningradsky Ave, GSP-3, Moscow, Russia, 1259930; lukushin@aol.com)

\section{VALUE DISGUISE IN THE INFORMATION FLOWS OF RUSSIAN POLITICAL PARTIES}

\footnotetext{
Abstract. The article presents the results of an applied political research devoted to the use of value disguise by Russian political parties - a modern technology of interaction with target groups in the digital space. Based on the use of automated social media analysis and cognitive mapping of digital party content, the scale, features and effects of such value masking have been determined. The authors conclude that the left turn in the development of public sentiments and expectations, which has emerged in recent years under the influence of the negative effects of the COVID-19 pandemic, is pushing political parties to change their own agenda, as well as to abandon established political positions in accordance with the current demands of a significant part of voters.

Keywords: political parties, information flows, social media analysis, value disguise, digital management, digital infrastructures, cognitive mapping
} 